\title{
Coexistence of Primary Biliary Cirrhosis and Inflammatory Bowel Disease
}

\section{Toru Shizuma*}

Department of Physiology, School of Medicine, Tokai University, Japan

\begin{abstract}
The coexistence of Primary Biliary Cirrhosis (PBC) and Inflammatory Bowel Disease (IBD) is uncommon although hepatobiliary complications in IBD patients are not rare. This report reviews the English and Japanese literature and covers reported cases of concomitant PBC and IBD. We identified 2 cases of concomitant PBC and Crohn's Disease (CD) and 18 cases of concomitant PBC and Ulcerative Colitis (UC). In most instances (15/18), IBD (CD or UC) developed before PBC, with the exception of 2 cases that were almost simultaneously diagnosed with both conditions. There is no evidence that UC cases with concomitant PBC are more severe than those without; however, the clinical features of concomitant PBC and CD are unclear due to few reports.
\end{abstract}

Keywords: Primary biliary cirrhosis; Inflammatory bowel disease; Crohn's disease; Ulcerative colitis

\section{Introduction}

Inflammatory Bowel Diseases (IBD), including Crohn's Disease (CD) and Ulcerative Colitis (UC), are chronic recurrent, and characterized by intestinal inflammation that appears to result from a complex of environmental and immune factors [1,2]. Approximately $25 \%$ of IBD patients exhibit symptoms below the age of 18 ; however, its diagnosis is frequently delayed until later in life $[1,2]$.

On the other hand, Primary Biliary Cirrhosis (PBC) is an autoimmune liver disease that presents with chronic cholestasis characteristic histological findings of non-suppurative destructive cholangitis; it progresses to liver fibrosis and cirrhosis [3,4]. PBC occurs more commonly in women than in men (female-to-male ratio of 9-10:1) and often in middle-age [3,4].

Although the development of extra intestinal manifestations during the course of IBD is well known, a controlled study indicated that $6.6 \%$ of UC patients and $1.9 \%$ of CD patients had at least 1 autoimmune disorder [5]. Cases of concomitant PBC and IBD are uncommon [6-22]. In addition, cases of concomitant PBC and CD appear to be extremely rare [21,22]; however, cases of concomitant $\mathrm{PBC}$ and UC have been sporadically reported [6-20]. Currently, it is uncertain whether concomitant $\mathrm{PBC}$ and IBD occurs by chance or has a common immunological basis [21]. As a result, there are few systematic literature reviews of concomitant PBC and IBD.

For this report, we conducted a literature search and review of cases of concomitant PBC and IBD (CD plus UC).

\section{Methods}

We aimed to review the English and Japanese literature describing these conditions and to summarize the findings in this report. A literature search was performed using the following keywords: (1) primary biliary cirrhosis and inflammatory bowel disease; (2) primary biliary cirrhosis and Crohn's disease; (3) primary biliary cirrhosis and ulcerative colitis. English and Japanese literature searches were performed using PubMed and Japana Centra Revuo Medicina (Igaku Chou Zasshi), respectively.

\section{Hepatobiliary manifestations in IBD patients}

Hepatobiliary manifestations in IBD have been described as Primary Sclerosing Cholangitis (PSC), cholangiocarcinoma, pericholangitis, fatty liver, gallstones, and autoimmune liver disease such as autoimmune hepatitis or PBC [15,19,21,23]. The incidence of hepatobiliary diseases with UC has been reported to be $3 \%-15 \%$ and up to $90 \%$ with abnormal liver histology at surgery or autopsy $[16,24]$. PSC is best known for hepatobiliary manifestation with UC, and the frequency of incidence of patients with concomitant PSC and IBD has been reported to be in the range of $2.4 \%-7.5 \%[10,16,23,25,26]$. Moreover, the severity of colitis has been reported to bear no relation to the coexistence of PSC [23].

On the other hand, Sjögren's syndrome, systemic sclerosis, and chronic thyroiditis also commonly occur concomitantly with PBC $[10,15,27,28]$. The precise frequency of IBD occurring concomitantly with $\mathrm{PBC}$ has been unclear.

\section{Concomitant PBC and IBD}

We identified 20 reported cases of concomitant PBC and IBD in 18 English and 2 Japanese reports. To the best of our knowledge, the first reported English case of concomitant PBC and UC was in 1985 by Kato et al. [7], (and the first reported Japanese case was in 1984 by Morimoto et al. [19].). The first reported English case of concomitant $\mathrm{PBC}$ and $\mathrm{CD}$ was in 2005 by Jang et al. [21]. The characteristics of these 20 cases are summarized in Table 1 . Of these, there were only 2 cases of concomitant $\mathrm{PBC}$ and $\mathrm{CD}$ and 18 cases of concomitant $\mathrm{PBC}$ and UC [7-22].

One characteristic of cases of concomitant PBC and UC has been the reported lower female-to-male ratio compared with that for $\mathrm{PBC}$ cases without UC $[13,21]$. In fact, out of the 20 cases of concomitant PBC and IBD cases, 8 cases (40\%) were male, and out of the 18 cases of concomitant $\mathrm{PBC}$ and UC, 7(39\%) were male (Table 1), thus indicating a higher than general frequency of occurrence in males. It has been suggested by some reports mentioned above that $\mathrm{PBC}$ is more common in women than in men, with a female-to-male ratio of 9-10:1 [3,4]. In

*Corresponding author: Toru Shizuma, Department of Physiology, Schoo of Medicine, Tokai University, 143, Shimokasuya, Isehara, Kanagawa, 259 1193, Japan, Tel : +81-0463-93-1121; Fax : +81-0463-93-6684; E-mail: shizuma@is.icc.u-tokai.ac.jp

Received April 01, 2014; Accepted April 18, 2014; Published April 25, 2014

Citation: Shizuma T (2014) Coexistence of Primary Biliary Cirrhosis and Inflammatory Bowel Disease. J Liver 3: 154. doi:10.4172/2167-0889.1000154

Copyright: (c) 2014 Shizuma T. This is an open-access article distributed unde the terms of the Creative Commons Attribution License, which permits unrestricted use, distribution, and reproduction in any medium, provided the original author and source are credited. 
Page 2 of 3

\begin{tabular}{|c|c|c|c|c|c|c|c|c|}
\hline Case & Sex & IBD & $\begin{array}{c}\text { Age at diagnosis of IBD } \\
\text { (years) }\end{array}$ & $\begin{array}{l}\text { Age at diagnosis of } \\
\text { PBC (years) }\end{array}$ & $\begin{array}{l}\text { IBD prior to } \\
\text { PBC }\end{array}$ & UC type & Complications & References \\
\hline 1 & $\mathrm{~F}$ & UC & 65 & $69 ?$ & + & Pancolitis & Chronic pancreatitis & [7] \\
\hline 2 & $\mathrm{~F}$ & UC & 47 & $48 ?$ & + & Proctitis & & [8] \\
\hline 3 & M & UC & 26 & 32 & + & Proctitis & & [8] \\
\hline 4 & M & UC & 44 & $52 ?$ & + & Proctitis & & [8] \\
\hline 5 & $\mathrm{~F}$ & UC & 28 & $40 ?$ & + & Left-sided colitis & & [8] \\
\hline 6 & $\mathrm{~F}$ & UC & 49 & 49 & Sim & Left-sided colitis & $\begin{array}{l}\text { Chronic myelocyic } \\
\text { leukemia }\end{array}$ & [9] \\
\hline 7 & M & UC & 40 & 45 & + & Left-sided colitis & & [10] \\
\hline 8 & $\mathrm{~F}$ & UC & $43 ?$ & 45 & + & Proctitis & Chronic pancreatitis & {$[11]$} \\
\hline 9 & $\mathrm{~F}$ & UC & 48 & $48 ?$ & + & Pancolotis & Renel cell carcinoma & [12] \\
\hline 10 & M & UC & 50 & 58 & + & Pancolotis & & [13] \\
\hline 11 & $\mathrm{~F}$ & UC & 36 & 68 & + & Pancolotis & & [13] \\
\hline 12 & $\mathrm{~F}$ & UC & 43 & 45 & + & Pancolotis & & [14] \\
\hline 13 & $\mathrm{M}$ & UC & 61 & 60 & - & Proctitis & & {$[15]$} \\
\hline 14 & $\mathrm{~F}$ & UC & 50 & 50 & Sim & Proctitis & & [16] \\
\hline 15 & M & UC & 77 & $78 ?$ & + & $?$ & Myasthenia gravis & [17] \\
\hline 16 & $\mathrm{~F}$ & UC & 43 & 31 & - & Left-sided colitis & & {$[18]$} \\
\hline 17 & $\mathrm{~F}$ & UC & $63 ?$ & 65 & + & Left-sided colitis & Chronic pancreatitis & [19] \\
\hline 18 & M & UC & 64 & 62 or 63 & - & Proctitis & & [20] \\
\hline 19 & M & $C D$ & 19 & 19 or 20 & + & & & [21] \\
\hline 20 & $\mathrm{~F}$ & $C D$ & 30 & 44 & + & & & [22] \\
\hline
\end{tabular}

UC: Ulcerative Colitis; CD: Crohn's Disease; F: Female; M: Male; Sim: Simultaneous

Table 1: Characteristics of 20 Patients with Concomitant Primary Biliary Cirrhosis and Inflammatory Bowel Disease.

contrast, UC has not been estimated to be a sex-specific disease; the female-to-male ratio for UC differs between 0.51 and $1.58[2,29]$.

The ratio of CD versus UC cases was 2:18 in the cases of concomitant PBC and IBD (Table 1) although a recent systematic review indicated that the prevalence of CD and UC in Western and European countries has been 90 and 505 per 100,000 and $319-322$ per 100,000, respectively $[1,2,29]$.

In most instances, (15/18) IBD developed before PBC; except in 2 cases, which were almost simultaneously diagnosed $[9,16]$. The concomitant diagnoses were made between the ages of 19 and 78 years. In the aforementioned 20 reported cases, the time interval between the development of PBC and IBD was 0-32 years (Table 1).

Antimitochondrial Antibodies (AMA or M2) are useful for the serological diagnosis of $\mathrm{PBC}$, and $90 \%-95 \%$ of $\mathrm{PBC}$ patients are AMA positive [30]. In a total of 20 cases of concomitant PBC and IBD, 2 cases (10\%) were AMA-negative although titers of M2 antibodies were not mentioned [16,21].

\section{IBD subgroup: cases of concomitant $\mathrm{PBC}$ and $\mathrm{CD}$}

Case reports of concomitant $\mathrm{PBC}$ and $\mathrm{CD}$ are extremely rare, even more so than those of PBC and UC. We identified 2 cases of concomitant $\mathrm{PBC}$ and $\mathrm{CD}$ in the English literature (Table 1) [6,21,22].

The 2 reported cases of concomitant $\mathrm{PBC}$ and $\mathrm{CD}$ were as follows:

Jang et al. [21] reported the case of a 19-year-old man who developed AMA-negative PBC after diagnosis of CD. His serological findings normalized a month after administration of ursodeoxycholic acid. Sisman et al. [22] reported the case of a 44-year-old female who developed AMA-positive PBC 14 years after CD diagnosis. She developed $\mathrm{PBC}$ during infliximab treatment for $\mathrm{CD}$, and liver enzymes and AMA levels normalized after cessation of infliximab. She had undergone a right hemicolectomy for ileocolonic CD.

\section{Possible mechanism of developing PBC following UC}

One of the accepted hypotheses for the pathogenesis of IBD is that the mucosal immune system exhibits an aberrant response towards luminal antigens such as commensal bacteria [18]. A chronic low-grade portal infection caused by UC leading to chronic biliary tract inflammation and fibrosis has been suggested as a pathogenic mechanism $[9,15]$. Some researchers have reported that lipoteichoic acid, a component of bacteria, may be involved in the pathogenesis of $\mathrm{PBC}$ and UC [18,31].

\section{IBD subgroup: cases of concomitant PBC and UC}

A retrospective population-based study of UC in Stockholm County in Sweden noted 2 cases of concomitant PBC out of 1274 UC patients [24]. Although some reports have suggested the possibility that the prevalence of PBC in UC patients is greater than that in general populations, it is currently unclear $[6,13]$.

In reports of concomitant $\mathrm{PBC}$ and UC, histological findings according to Scheuer's classification were mentioned. Staging of PBC was as follows: 6 cases at stage I , 1 at stage II , 2 at stage III, 1 at stage III $\sim$ IV. No cases of liver failure or death due to PBC were found although 1 case of suspected liver cirrhosis with ascites was noted [15]. Moreover, no cases received liver transplantation.

Eighteen cases of concomitant PBC and UC were reported as follows: 5 cases of pancolitis, 5 of left-sided colitis, 7 of proctitis, and 1 unclear (Table 1). In contrast, PSC patients tended to have pancolitis [10]. There were no cases with flare-up of UC after the onset of PBC. Moreover, colitis with concomitant $\mathrm{PBC}$ and $\mathrm{UC}$ has been reported to be less severe than that typically seen in isolated UC $[10,15]$. Most cases of concomitant $\mathrm{PBC}$ and UC that went into remission were treated with amino salicylates, corticosteroids or both [20]. Only 1 case resulted in surgery because of persistent inflammation of UC before the onset of PBC. Moreover, severe complications, such as toxic megacolon or death due to colitis, have not been reported in cases of concomitant $\mathrm{PBC}$ and UC [14-20]. 
On the other hand, it is noteworthy that 3 of the 18 cases of concomitant PBC and UC were also diagnosed with chronic pancreatitis $[7,11,19]$. One of the reasons may be that an endoscopic retrograde cholangiopancreatography examination was carried out for differentiation of PSC in these cases.

\section{References}

1. Laass MW, Roggenbuck D, Conrad K (2014) Diagnosis and classification of Crohn's disease. Autoimmun Rev 13: 467-471.

2. Conrad K, Roggenbuck D, Laass MW (2014) Diagnosis and classification of ulcerative colitis. Autoimmun Rev 13: 463-466.

3. Hohenester S, Oude-Elferink RP, Beuers U (2009) Primary biliary cirrhosis. Semin Immunopathol 31: 283-307.

4. Mohan N, Lindor KD (2014) Primary biliary cirrhosis in adults. Expert Rev Gastroenterol Hepatol 8-427-433.

5. Stevens HP, Ostlere LS, Rustin MH (1994) Systemic lupus erythematosus in association with ulcerative colitis: related autoimmune diseases. $\mathrm{Br} \mathrm{J}$ Dermatol 130: 385-389.

6. Yoshida EM, Erb SR (1993) Primary biliary cirrhosis and inflammatory bowel disease. Am J Gastroenterol 88: 1977-1978.

7. Kato $\mathrm{Y}$, Morimoto H, Unoura M, Kobayashi K, Hattori N, et al. (1985) Primary biliary cirrhosis and chronic pancreatitis in a patient with ulcerative colitis. J Clin Gastroenterol 7: 425-427.

8. Bush A, Mitchison H, Walt R, Baron JH, Boylston AW, et al. (1987) Primary biliary cirrhosis and ulcerative colitis. Gastroenterology 92: 2009-2013.

9. Akahoshi K, Miyata Y, Hashimoto M, Koga S, Chijiiwa Y, et al. (1992) A case of combined primary biliary cirrhosis, ulcerative colitis and chronic myelocytic leukemia. Gastroenterol Jpn 27: 252-257.

10. Lever E, Balasubramanian K, Condon S, Wat BY (1993) Primary biliary cirrhosis associated with ulcerative colitis. Am J Gastroenterol 88: 945-947.

11. Veloso FT, Dias LM, Carvalho J, Fraga J, Saleiro J (1993) Ulcerative colitis, primary biliary cirrhosis, and chronic pancreatitis: coincident or coexistent? J Clin Gastroenterol 16: 55-57.

12. Satsangi J, Marshall J, Roskell D, Jewell D (1996) Ulcerative colitis complicated by renal cell carcinoma: a series of three patients. Gut 38: 148-150.

13. Koulentaki M, Koutroubakis IE, Petinaki E, Tzardi M, Oekonomaki H, et al (1999) Ulcerative colitis associated with primary biliary cirrhosis. Dig Dis Sci 44: 1953-1956.

14. Ohge H, Takesue $\mathrm{Y}$, Yokoyama T, Hiyama E, Murakami $\mathrm{Y}$, et al. (2000) Progression of primary biliary cirrhosis after proctocolectomy for ulcerative colitis. J Gastroenterol 35: 870-872.

15. Nakayama M, Tsuji H, Shimono J, Azuma K, Ogata H, et al. (2001) Primary biliary cirrhosis associated with ulcerative colitis. Fukuoka Igaku Zasshi 92 354-359.

16. Xiao WB, Liu YL (2003) Primary biliary cirrhosis and ulcerative colitis: a case report and review of literature. World J Gastroenterol 9: 878-880.

17. McCann P, Pramanik A (2004) Dysphagia and unexpected myasthenia gravis associated with primary biliary cirrhosis, ulcerative colitis and vitiligo. $\mathrm{J}$ Am Geriatr Soc 52: 1407-1408

18. Tada F, Abe M, Nunoi H, Azemoto N, Mashiba T, et al. (2011) Ulcerative colitis complicated with primary biliary cirrhosis. Intern Med 50: 2323-2327.

19. Morimoto $H$, Kato $Y$, Ishida $Y$, Unoura M, Sawabu N, et al. (1984) [Primary biliary cirrhosis and chronic pancreatitis in a patient with ulcerative colitis] Nihon Shokakibyo Gakkai Zasshi 81: 117-120.

20. Arai O, Ikeda H, Mouri H, Notohara K, Matsueda K (2010) Two cases of inflammatory bowel disease diagnosed in the course of primary biliary cirrhosis. Nihon Shokakibyo Gakkai Zasshi 107: 900-908.

21. Jang HJ, Kim GS, Eun CS, Kae SH, Jang WY, et al. (2005) Development of primary biliary cirrhosis in a patient with Crohn's disease: a case report and review of the literature. Dig Dis Sci 50: 2335-2337.

22. Sisman G, Erzin Y, Bal K (2013) Primary biliary cirrhosis developing in a patient with Crohn's disease during the course of infliximab treatment: the first case in the literature. J Crohns Colitis 7: e397-398.

23. Lichtenstein DR (2011) Hepatobiliary complications of inflammatory bowe disease. Curr Gastroenterol Rep 13: 495-505.

24. Monsén U, Sorstad J, Hellers G, Johansson C (1990) Extracolonic diagnoses in ulcerative colitis: an epidemiological study. Am J Gastroenterol 85: 711-716.

25. Raj V, Lichtenstein DR (1999) Hepatobiliary manifestations of inflammatory bowel disease. Gastroenterol Clin North Am 28: 491-513.

26. Ahmad J, Slivka A (2002) Hepatobiliary disease in inflammatory bowel disease Gastroenterol Clin North Am 31: 329-345.

27. Schifter T, Lewinski UH (1997) Primary biliary cirrhosis and systemic lupus erythematosus. A rare association. Clin Exp Rheumatol 15: 313-314.

28. Islam S, Riordan JW, McDonald JA (1999) Case report: a rare association of primary biliary cirrhosis and systemic lupus erythematosus and review of the literature. J Gastroenterol Hepatol 14: 431-435.

29. Molodecky NA, Soon IS, Rabi DM, Ghali WA, Ferris M, et al. (2012) Increasing incidence and prevalence of the inflammatory bowel diseases with time, based on systematic review. Gastroenterology 142: 46-54.

30. Shizuma T, Kuroda H (2011) A case of primary biliary cirrhosis which developed eight years after diagnosis of systemic lupus erythematosus. Intern Med 50 321-324.

31. Haruta I, Hashimoto E, Kato Y, Miyakawa H, Shibata N, et al. (2006) Intrahepatic biliary epithelial cell damage and inflammation in portal tract in association with chronic colitis-harboring TCRalpha(-/-) mice. Hepatol Res 34: 3-8. 